\title{
Ramiz Galvão, historiador e bibliotecário: práticas e lugares da produção historiográfica no Brasil de fins do século XIX e início do século $\mathrm{XX}^{*}$
}

\author{
Ramiz Galvão, historian and librarian: Practices and places of \\ historiographical production in Brazil from the end of the $19^{\text {th }}$ century \\ to the beginning of the $2 \mathrm{O}^{\text {th }}$ century
}

\author{
Adriana Mattos Clen Macedo \\ adrianaclen@yahoo.com.br \\ Professora adjunta A \\ Universidade de Brasília \\ SQN 402, bloco A, apto. 304, Asa Norte \\ 70834-010 - Brasília - Distrito Federal \\ Brasil \\ Ana Paula Sampaio Caldeira \\ anapaula.sampaiocaldeira@gmail.com \\ Professora adjunta I \\ Universidade Federal de Minas Gerais \\ Rua Sena Madureira, 404, apto 203, Bairro Ouro Preto \\ 31340-000 - Belo Horizonte - Minas Gerais \\ Brasil
}

\section{Resumo}

Este artigo parte das questões propostas por Michel de Certeau em seu texto "A operação historiográfica" para examinar a escrita da história no Brasil entre as décadas de 1870 e 1930. Um intelectual específico desse período, Benjamin Franklin Ramiz Galvão, nos servirá como fio condutor para essa análise. Embora não ocupe hoje lugar de destaque no panteão dos historiadores nacionais, Ramiz Galvão foi, em sua época, um intelectual-chave e uma referência pela sua atuação em diversas instituições de saber do Império e da República, como o Instituto Histórico e Geográfico Brasileiro e a Biblioteca Nacional. Analisando justamente a atuação desse agente nessas instituições, procuraremos ressaltar dois aspectos: em primeiro lugar, como a tarefa de compor um passado para a nação brasileira na virada do século XIX para o século XX envolvia diversas práticas, agentes e espaços; e, em segundo lugar, como sua figura é representativa de uma mudança nas regras do fazer historiográfico, mudanças essas que nos ajudam a compreender o próprio lugar que esse intelectual ocupa na memória disciplinar.

\section{Palavras-chave}

Operação historiográfica; Instituto Histórico e Geográfico Brasileiro; escrita da história; intelectuais.

\begin{abstract}
This paper takes the issues proposed by Michel de Certeau in his text "The Historiographical Operation" to analyze the writing of Brazil's history between the 1870's and the 1930's. A particular intellectual of this period, Benjamin Franklin Ramiz Galvão, will be our guide for this analysis. Although he does not currently hold a central position in the pantheon of national historians, at his time Ramiz Galvão was a key-intellectual and a reference for his work in several knowledge institutions during the imperial and republican periods, such as the Brazilian Institute of History and Geography and the National Library. By analyzing his performance in these institutions, we seek to highlight two aspects: first, how the task of writing a past for Brazilian nation in the transition from the $19^{\text {th }}$ century to the $20^{\text {th }}$ century encompassed several practices, agents and places; and second, how he is representative of a change in the rules of historiographical modus operandi. This change helps us understand why he holds a position in the discipline memory.
\end{abstract}

Keywords

Historiographical operation; Instituto Histórico e Geográfico Brasileiro; Writing of history; Intellectuals.

Recebido em: 20/10/2016

Aprovado em: 28/11/2016

${ }^{*}$ Esta pesquisa contou com financiamento da Faperj. 
Qualquer trabalho que pretenda formular interrogações sobre a escrita da história em suas múltiplas dimensões dificilmente poderá fazê-lo sem se deparar com a obra de Michel de Certeau. Autor bastante lido entre os historiadores brasileiros, os livros de Certeau abriram caminhos para um universo amplo de pesquisas, que pode ser condensado, de acordo com Eric Maigret, em três grandes direções: a epistemologia da história, a sócio-antropologia das religiões e as teorias da ação e recepção (MAIGRET 2000).

Neste artigo, partiremos da reflexão proposta por Certeau acerca dos fundamentos da "operação historiográfica" para pensar a escrita da história no Brasil das últimas décadas do século XIX e primeiras do XX. Como se sabe, a compreensão da historiografia como uma "operação" permite considerar sua relação com um lugar de produção que Ihe submete imposições, ao mesmo tempo em que possibilita o próprio trabalho do historiador. É justamente nesse lugar social que as regras da produção historiográfica se sobrepõem ao profissional da história e legitimam seu texto. Espaço em que se realiza uma espécie de "contrato" entre os historiadores e seus pares, o lugar social pode ser entendido, de maneira mais circunscrita, como a instituição de saber que permite e limita, silenciosamente, as regras do jogo "historiográfico" - o que significa, em última instância, validar quem é ou não historiador, bem como o que pode ou não pode ser considerado como obra historiográfica.

Lugar social é um conceito crucial no pensamento de Certeau, que, em alguma medida, dialoga com autores como Michel Foucault e suas reflexões acerca das regras de formação dos discursos (FOUCAULT 1997; 2010). Tal discussão permite, inclusive, dimensionar as atividades de pesquisa e ensino exercidas pelos historiadores nos dias atuais, bem como seu papel como agente que confere presença ao passado e que, por isso, tem um compromisso ético com a sociedade. Afinal de contas, na operação que realiza, o historiador enterra os mortos de uma sociedade e, paralelamente, estabelece um lugar para os vivos. Assim, a atualidade de Certeau passa, entre outras questões, pela reflexão acerca da subjetividade do historiador, pela atenção conferida à dimensão ética do seu trabalho e, também, pela necessidade de entender o significado que a historiografia como prática possui numa dada sociedade (CERTEAU 1982, p. 65-109).

Gostaríamos de nos centrar, em especial, nesse último ponto. No Brasil da virada do século XIX para o XX, momento em que ainda não existiam os cursos universitários de história, as regras do discurso historiográfico e o lugar por excelência para o desenvolvimento de uma escrita e reflexão sobre o passado remetiam para o Instituto Histórico e Geográfico Brasileiro (IHGB), instituição que foi e continua sendo objeto de diversos estudos sobre a escrita da história no Brasil oitocentista. ${ }^{1}$ Sem negar a centralidade do IHGB na definição do que era

\footnotetext{
${ }_{1}$ Muitos são os trabalhos que se dedicaram a pensar a escrita da história no interior do Instituto Histórico e Geográfico Brasileiro. Vale ressaltar o estudo pioneiro de Manoel Salgado Guimarães (1988; 2011), além dos trabalhos de Temístocles Cézar (2003; 2004) e Lúcia Paschoal Guimarães (1995; 2005; 2006a; 2006b). Estes três autores, além de terem desenvolvido suas próprias pesquisas sobre o IHGB, também orientaram importantes trabalhos que tomaram o Instituto Histórico e alguns de seus membros como objeto de estudos.
} 
ser historiador naquele momento e na delimitação das tarefas que compunham esse ofício, temos como principal objetivo abordar o fazer historiográfico a partir de outras atividades e instituições imersas na tarefa de estabelecer os contornos da história nacional. Estas, particularmente, eram lugares de produção historiográfica que também ajudavam a caracterizar a identidade historiadora e o significado de se produzir história no Brasil no período aqui recortado.

Tomaremos como fio condutor de nossa análise um personagem específico, Benjamin Franklin Ramiz Galvão. Embora não ocupe, hoje, lugar de destaque no "panteão" dos historiadores nacionais, esse letrado foi um intelectual-chave e uma referência em sua época pela atuação em diversas instituições de saber imperiais e republicanas, como o próprio IHGB, mas também a Biblioteca Nacional (BN), o Colégio Pedro II e a Academia Brasileira de Letras ( $A B L$ ). Nascido no Rio Grande do Sul em 1846, Ramiz Galvão mudou-se para o Rio de Janeiro ainda criança. Em sua juventude, como aluno do Colégio Pedro II, começou a tecer sua rede de sociabilidades e se tornou conhecido do Imperador, que costumava frequentar os exames finais daquela que era uma das principais instituições imperiais de ensino. Em 1870, aos 24 anos, foi nomeado pelo próprio monarca para dirigir a Biblioteca Nacional. Também pelas mãos de D. Pedro II, em 1872 assumiu o posto de sócio do IHGB, tendo exercido, ao mesmo tempo, essas duas funções e o magistério. Permaneceu na Biblioteca Nacional até 1882, desenvolvendo um projeto de modernização da instituição, o que fez da passagem pela BN uma marca em sua biografia. Já atuante no IHGB durante o Império, foi na República que passou a ocupar cargos estratégicos naquela Casa, tornando-se diretor da Revista do IHGB e orador perpétuo do Instituto. Morreu em 1938, aos 92 anos.

Tanto no Instituto Histórico quanto na Biblioteca Nacional, Ramiz Galvão foi alguém que arregimentou projetos, coordenou pessoas e atuou como historiador. Tornou-se, portanto, um nome bastante exemplar da diversidade das práticas e dos lugares de produção historiográfica no Brasil de sua época, como veremos adiante.

\section{Um historiador na Biblioteca Nacional}

"Em história, tudo começa com o gesto de separar, de reunir, de transformar em documento certos objetos distribuídos de outra maneira" (CERTEAU 1982, p. 81). Com essa afirmação, Michel de Certeau remete ao intrincado processo em que objetos de diversos tipos são transformados em fontes históricas: materiais que, em sua época, foram produzidos com uma finalidade, mas que, ao serem separados e reunidos, são transformados em acervos para o historiador. Se a moderna escrita da história está assentada em fontes e no trabalho em arquivo (elementos que vieram substituir a autoridade que alguns autores clássicos tinham quando a história era concebida de uma maneira mais próxima da retórica), isso não significa dizer que a constituição de acervos e de coleções seja algo que data da disciplinarização da história, no século XIX. Como nos mostram os trabalhos de Arnaldo Momigliano (2004; 2014), Anthony Grafton (1998), Blandine Kriegel (1988) e do próprio Michel de Certeau, tal prática, bem como o método de crítica documental, remetem à tradição antiquária e erudita. 
Embora tenha sido posta à margem quando da construção de uma memória disciplinar, essa tradição legou à história com pretensões científicas justamente o cuidado com as fontes e a formação de conjuntos documentais.

Ao mesmo tempo, e de modo associado, museus, arquivos e bibliotecas tornaram-se, durante o século XIX, espaços por excelência de salvaguarda e proteção de documentos que foram patrimonializados e entendidos como testemunhos de um passado nacional comum a uma determinada coletividade. Por outro lado, como lembra Arlette Farge, trata-se de um processo que se assenta também na ausência e na falta, na medida em que é fruto de uma seleção que permitiu que certos materiais sobrevivessem ao tempo, enquanto outros foram legados ao esquecimento, ou mesmo ao desaparecimento (FARGE 1989). Certamente, esse balanço entre a lembrança e o esquecimento continua ainda hoje sendo constitutivo do trabalho do historiador, que seleciona os documentos que interessam às suas pesquisas. Assim, ao chamarmos a atenção para esse movimento que envolve a constituição de arquivos, como também de práticas que caracterizam o fazer do profissional da história, gostaríamos de destacar uma questão geral e outra mais específica, que servem aos interesses deste artigo.

A primeira delas diz respeito à forma como foi concebido o ofício do historiador a partir da constituição da história como disciplina: um ofício, como dito acima, profundamente marcado pelo trabalho com as fontes e os testemunhos de uma época, os quais passaram por um processo de mudança de estatuto, envolvendo práticas de seleção e de organização até se constituírem como arquivos. Ao atentar para esse ponto, Certeau parece chamar a atenção para a dimensão histórica do próprio trabalho desse profissional e para a necessidade de considerar o processo pelo qual os acervos são constituídos. ${ }^{2}$ Disto decorre a segunda questão que gostaríamos de destacar, a qual diz respeito ao personagem aqui estudado. Se há algo que caracterizou a atuação de Ramiz Galvão como diretor da Biblioteca Nacional, esse traço foi o seu empenho em organizar arquivos e constituir coleções documentais, elemento central em seu projeto de fazer da BN uma instituição não só de salvaguarda de acervos, como também um espaço a serviço dos historiadores.

Durante a gestão de Ramiz Galvão, um de seus principais objetivos foi tornar a Biblioteca um ambiente útil para os intelectuais da Corte. Assim, era necessário que a Casa assumisse que, junto a armazenar livros, manuscritos e materiais iconográficos, uma de suas funções precípuas fosse auxiliar investigações e estudos de toda natureza. Para isso, ele trabalhou para que a instituição modernizasse seu sistema de funcionamento e, sobretudo, se dedicou a levar adiante um projeto de organização interna da biblioteca e de disponibilização de seu acervo a um público de especialistas. Nesse sentido, os

\footnotetext{
2 Paul Ricoeur, trabalhando de maneira própria com a noção de operação historiográfica, também parece chamar a atenção para essa questão, especialmente quando considera o processo que leva do testemunho à prova documental, começando na memória declarada, passando pelo arquivo e chegando, enfim, à prova. É justamente aí, segundo Ricoeur, que a história se diferencia da memória, na medida em que objetiva os testemunhos, transformando-os em documentos, o que significa passar pelo crivo da verificação e da autenticidade (RICOEUR 2007; DOSSE 2010).
} 
novos regulamentos da BN, que entraram em vigor a partir de 1876, dividiramna em três seções: impressos e cartas geográficas, manuscritos e estampas. 0 mais importante, porém, foi a criação, no mesmo ano, de um veículo editorial para servir de meio de divulgação dos documentos ali existentes: os Anais da Biblioteca Nacional. A publicação desse periódico acabava por coroar aquilo que seria, para Ramiz, a sua função como bibliotecário. Mas caracterizava também a sua prática como historiador em exercício na BN, pois cabia a ele desenterrar os tesouros esquecidos, organizá-los, arquivá-los e, por fim, trazê-los a público para que possibilitassem toda a sorte de pesquisas. Portanto, era atribuição do bibliotecário ser ainda um editor:

Ele [o bibliotecário] examina, ordena e classifica como o naturalista; ele compara os textos, e decide a primazia, como o crítico; restaura os monumentos injustamente esquecidos e exuma as relíquias do passado como o arqueólogo [...]; arquiva, comenta e ilumina de notas as obras hodiernas para auxiliar as investigações do futuro, dá o fio de Ariadne a toda a sorte de pesquisas [...]; ao literato fornece e aponta os modelos e as fontes, ao sábio faculta os anais das academias, ao artista os materiais da composição, ao político os documentos da administração dos Estados; em suma, não há trabalhador no imenso campo da ciência profana ou sagrada ou no domínio das artes, a quem ele não preste o seu braço, não há monumento literário de vulto, para cuja construção ele não concorra com pedras angulares (GALVÃO 1887, p. 108).

Como editor dos Anais da Biblioteca Nacional, Ramiz Galvão conduziu esse periódico de maneira a sintonizá-lo em um projeto de biblioteca, definindo de maneira bastante clara os objetivos da publicação. Primeiramente, pretendiase com ela formar um cânone das grandes coleções existentes na BN. ${ }^{3}$ Esse objetivo expandiu-se e consolidou-se quando os Anais publicaram, em 1881, 0 Catálogo da Exposição de História e Geografia do Brasil, com um levantamento inédito de documentos pertencentes a diversas instituições e particulares. Responsável tanto por um quanto pelo outro, os Anais e o Catálogo, Ramiz atuou não só na organização que conferiu significado ao acervo existente na Biblioteca, como também na definição e patrimonialização dos documentos tidos por indispensáveis para o estudo da história pátria. Assim, a partir do lugar que ocupava na BN, ele teve um papel central na publicização e divulgação de determinados documentos, esperando, com isso, elucidar pontos acerca do passado nacional e alinhar o periódico com as demandas de uma escrita da história pautada em fontes.

Mas, podemos falar ainda de uma terceira função envolvendo os Anais da Biblioteca Nacional: a de promover, dentro e fora do país, a própria Casa, inserindo-a na comunidade científica e letrada internacional, dando legitimidade

\footnotetext{
3 Os Anais da Biblioteca Nacional publicavam não apenas documentos relativos à história pátria, dando prioridade aos manuscritos, mas também estudos, em sua maioria assinados pelos funcionários da instituição. O periódico teve também um papel muito importante na formação de um cânone das principais coleções da BN, como o acervo do abade Diogo Barbosa Machado e as cartas do padre José de Anchieta, além da coleção Camoneana e a de Alexandre Rodrigues Ferreira, todas elas catalogadas e analisadas em suas páginas. Eram publicadas ainda traduções (como a que Batista Caetano Almeida Nogueira fez de um manuscrito em língua guarani), trabalhos acerca de "estampas curiosas" existentes no acervo e estudos bibliográficos. Para uma análise mais detalhada acerca dos Anais da Biblioteca Nacional, ver: Caldeira (2016).
} 
ao trabalho realizado ali dentro e construindo sua imagem como espaço de saber e investigação que, inclusive, permitiria ao Brasil acompanhar o movimento científico, literário e histórico das nações mais adiantadas. É justamente aí que reside a articulação entre o empreendimento editorial dos Anais, o projeto de biblioteca pensado por Ramiz Galvão e um projeto mais amplo de nação moderna, que envolvia outras instituições.

Nesse sentido, a passagem citada acima, escrita pelo próprio Ramiz, é reveladora da forma como ele mesmo dava sentido ao trabalho que realizava no interior da BN. Ele é preciso quanto à centralidade da ação de certo tipo de investimento intelectual: "subterrâneo", como todo bom alicerce de uma sólida construção. Com profissionais qualificados, novos estatutos e a publicação dos Anais, o diretor buscava fazer da Biblioteca Nacional um local de pesquisa histórica e uma instituição guardiã e difusora do passado nacional, presente na materialidade dos documentos que possuía e que, desde 1876, passavam a ser publicados. Lidar com estes documentos, estudá-los, classificá-los e catalogálos não era trabalho para qualquer um, mas requeria alguém que tivesse uma formação que o capacitasse para aquele serviço. Não por acaso, Ramiz Galvão buscou reformular seus quadros, formando uma equipe de trabalho que contava com nomes como Capistrano de Abreu, Alfredo do Vale Cabral, João Saldanha da Gama e José Alexandre Teixeira de Melo.

Como não podemos esquecer, Ramiz também fazia parte do IHGB. Isso significa dizer que ele estava familiarizado com as leituras e propostas daquele que era então o espaço de legitimação da escrita da história no Brasil. Mais ainda, estava também atento à aquisição de documentos históricos e à centralidade desse tipo de material para o trabalho do historiador. Como vimos, ele assumiu o posto na BN e entrou para a agremiação quase no mesmo momento, tendo as duas instituições como espaços privilegiados na sua formação como historiador - ainda que sua atuação mais forte no espaço do IHGB viesse a se dar somente a partir da República. Entendemos que, durante a década de 1870, o Instituto Histórico era para ele um lugar a partir do qual ganhava referenciais para exercer seu papel como historiador, enquanto a BN era o ambiente em que essa função efetivamente se exercia, mesmo porque o trabalho ocupava boa parte de seus dias, praticamente exigindo dele exclusividade. Ou seja, entendemos que foi nos salões da Biblioteca que ele se fez historiador, no trabalho cotidiano, realizado em equipe, com os documentos, na atuação como editor de obras e promotor de eventos, nos estudos que possibilitava e encomendava e na tarefa de divulgar o Brasil para os brasileiros e os estrangeiros. Se ao final de sua vida Ramiz já era visto como um intelectual "antiquado", nas décadas de 1870 e 1880 podemos dizer que suas ações representavam a modernidade dos estudos históricos no país.

Assim, tomando de empréstimo uma expressão utilizada por José Honório Rodrigues ao se referir ao momento em que Capistrano de Abreu atuou como oficial da Biblioteca Nacional, consideramos a BN uma espécie de "laboratório da história" para um intelectual como Ramiz Galvão (RODRIGUES 1954, p. XXXIX$X L)$. Concebida como um espaço de produção de conhecimento, era nela que 
Ramiz Galvão e todo o grupo de funcionários coordenado por ele atuavam como os "especialistas" que faziam esse laboratório funcionar, testavam possibilidades, desenvolviam projetos e colocavam procedimentos em prática. Mais do que organizar um arquivo, a equipe se empenhou em formar esse arquivo, selecionar e estabelecer uma ordem para os rastros do passado, colocando-os a serviço de alguém, o profissional da história.

É importante destacar que fazer da BN um espaço afinado com as demandas do moderno conhecimento histórico não significava, de modo algum, a intenção de rivalizar com o IHGB. Pelo contrário: o objetivo era ter com ele uma relação dialógica. Ambas as instituições, juntas, possibilitariam a escrita de uma história nacional e promoveriam o Brasil para os brasileiros e os estrangeiros. Nesse contato e na circulação pelos dois espaços, as relações mantidas no interior do Instituto poderiam fortalecer os projetos de Ramiz Galvão na BN.

\section{Um bibliotecário no IHGB}

A validação dos métodos empregados por Ramiz Galvão em trabalhos classificatórios, desde a organização de catálogos e exposições na Biblioteca Nacional, alcançou seu ponto máximo com uma série de publicações e congressos fomentados pelo Instituto Histórico e Geográfico Brasileiro, já no século XX. O bibliotecário tinha se afastado das atividades na agremiação um pouco antes de 1882, quando foi nomeado para o cargo de preceptor dos príncipes imperiais. Só em 1909 retomou com regularidade suas tarefas no Instituto, após a sua eleição como sócio efetivo, já sob a presidência do Barão do Rio Branco. Três anos depois, ele teve uma ascensão progressiva, assumindo a vaga de orador perpétuo, a direção da Revista do IHGB e a coordenação de diversos projetos acadêmicos.

Nesse mesmo momento, o Instituto passava por uma renovação interna, graças à atuação de três intelectuais que formavam uma espécie de "trindade" dentro da Casa: o presidente Afonso Celso, o secretário Max Fleiüss e o orador Ramiz Galvão. ${ }^{4}$ Eles teriam orientado todas as estratégias de atuação da agremiação entre 1912 e 1938 e poderiam ser caracterizados pelas suas posições a um só tempo conservadoras e progressistas. Conforme Lucia Maria Paschoal Guimarães (2006b, p. 62-3), "reformadores, eles inovavam sem romper com o passado e suas tradições. Patriotas extremados, faziam sucessivas profissões de fé no futuro do país". 5 Sobre as atividades específicas de Ramiz na agremiação, Guimarães afirma que "suas contribuições à historiografia são bastante restritas", posição particularmente justificada pelas avaliações do historiador e

\footnotetext{
${ }^{4}$ A ideia de uma "Trindade do Silogeu", que modificou o perfil do IHGB após o fim do mecenato imperial e, com isso, sustentou as iniciativas acadêmicas, foi discutida por Lúcia Maria Paschoal Guimarães. Para a autora, os empreendimentos de grande porte como o Primeiro Congresso de História Nacional (1914), o Dicionário Histórico, Etnográfico e Geográfico do Brasil (1915-1922) e a concepção de uma Faculdade de Filosofia e Letras (1916-1921) foram sinais das novas práticas historiográficas e do conhecimento histórico produzido pela instituição, que, em sua análise, estão relacionadas à reabilitação da Revolução Pernambucana (1817) e à descoberta dos originais da História da Independência, de Francisco Adolfo de Varnhagen (que seria publicada pela primeira vez em 1916, na própria Revista do IHGB) (Cf.: GUIMARÃES 2006b).

${ }^{5} \mathrm{Em}$ seu estudo acerca do IHGB durante o período republicano, Hugo Hruby procura matizar um pouco essa ideia, que associa o soerguimento do IHGB às presidências de Rio Branco e Afonso Celso. Ele destaca como a ampliação do ritmo de trabalho no interior da instituição já poderia ser percebida desde a gestão de Olegário Herculano de Aquino e Castro, entre 1891 e 1906 (HRUBY 2009).
} 
crítico literário Wilson Martins e pela valorização do perfil de bibliófilo e erudito que conquistara na administração da Biblioteca Nacional. ${ }^{6}$ Para ela, o trabalho deste acadêmico era caracterizado pela edição de bibliografias e periódicos, pela realização de pesquisas documentais e pela redação de artigos, mas suas produções não fornecem maiores indícios sobre o seu conceito de história (GUIMARÃES 2006b, p. 70).

Interpretação semelhante já aparecia em A pesquisa histórica no Brasil, escrita na década de 1950 por José Honório Rodrigues, na qual a vida intelectual de Ramiz Galvão é percebida pelas suas atividades administrativas, conferindo menor centralidade à análise de sua produção escrita. O perfil de organizador e executor de projetos institucionais durante o período monárquico, como a Exposição de História do Brasil e seu Catálogo, deu a ele experiência para seguir projetos semelhantes durante a República, como a direção da Associação do Quarto Centenário do Descobrimento do Brasil. Este cargo Ihe permitiu organizar conferências em parceria com vários intelectuais para comemorar a data e defender uma versão da história a partir da matriz portuguesa. ${ }^{7}$ Em seguida, a sua atuação no IHGB é renovada pela participação no Primeiro (1914) e no Segundo (1931) Congressos de História Nacional (1931).

A larga atuação de Ramiz, que ainda contemplou cargos na educação pública, ${ }^{8}$ representa um desafio para a discussão teórica das suas obras. A diversidade de suas atividades corresponde ao fracionamento dos seus textos, que também possuem a particularidade de terem sido escritos de acordo com a sua ampla erudição. Desde os seus trabalhos de juventude, percebe-se a prioridade dada por ele à pesquisa documental, especialmente através da busca de fontes em arquivos e bibliotecas e da referência direta aos autores que se aproximavam e divergiam das suas opiniões. A prática e a escrita histórica não estão distantes daquelas defendidas e compartilhadas pelos outros sócios do IHGB. Ramiz Galvão respeitava as tradições historiográficas da agremiação e esteve à frente dos novos projetos da instituição nas primeiras décadas do regime republicano, atuando na presidência de comissões, na organização de

\footnotetext{
6 "Wilson Martins faz apenas três referências: o estudo biográfico sobre frei Camilo de Monserrate [...]; uma tradução para o português da edição francesa da "Retirada da Laguna" e a monografia 'O púlpito no Brasil' [...]" (GUIMARÃES 2006b, p. 70). Sobre a análise do crítico literário, consultar Martins (1950, v. 6, p. 357). 7 No âmbito dessa associação, destacamos o contato entre Ramiz Galvão e Capistrano de Abreu. Para o livro do Quarto Centenário, este autor reproduziu a sua tese apresentada no Colégio Pedro II para o concurso ao cargo de professor de história e corografia do Brasil. Tanto na tese como no artigo, Capistrano discutiu as origens da história brasileira, tendo a acuidade de elucidar informações encontradas em impressos e manuscritos, além de confrontar teses sobre o passado já sedimentadas pela produção historiográfica do século XIX. A ideia de descobrimento não se reduziu à definição precisa de uma data, ela também era entendida como um roteiro espacial da ocupação do território através do movimento de interiorização do povoamento (Cf.: ASSOCIAÇÃO 1900-1910, v. 1).

${ }^{8}$ Em fevereiro de 1890, Ramiz Galvão ocupava o cargo de Inspetor Geral da Instrução Primária e Secundária do Distrito Federal por indicação de Benjamin Constant, Ministro e Secretário de Estado e dos Negócios da Instrução Pública, Correios e Telégrafos durante o governo provisório do marechal Deodoro da Fonseca. Cabe ressaltar que Galvão exerceu diversas funções relacionadas ao magistério ao longo do Império e da República, de maneira que este tipo de atuação marcou profundamente a sua biografia, entendida pelos seus biógrafos e por ele mesmo como uma espécie de "missão" civilizatória e patriótica. Ainda no Império, Galvão lecionou Grego e Retórica no Colégio Pedro II, foi preceptor dos príncipes imperiais e ensinou Zoologia e Botânica na Faculdade de Medicina. Na República, foi diretor da Instrução Primária e Secundária (1891-1893), vice-reitor (1891) e presidente do Conselho Superior de Ensino (1919), professor do Ginásio Nacional do Rio de Janeiro (1897-1900), diretor do Asilo Gonçalves de Araújo (1899-1931) e reitor da Universidade do Rio de Janeiro (1921-1925).
} 
eventos e publicações e também arregimentando pessoas. ${ }^{9}$ Há que se considerar ainda que ele foi um intelectual que viveu 92 anos, o que significa dizer que suas próprias concepções a respeito de questões historiográficas sofreram modificações e que não foram normatizadas durante a sua atuação como diretor da Biblioteca Nacional. Como seria natural, seu ímpeto também variou ao longo do tempo, e, ao final da vida, já bastante idoso, dedicou-se mais aos trabalhos ligados à memória do Instituto Histórico e menos às tarefas de organização de eventos e programas editoriais, que marcaram o período mais relembrado da sua carreira.

No Primeiro Congresso de História Nacional, organizado pelo IHGB em 1914, Ramiz Galvão definiu o regulamento do evento e a divisão em sessões temáticas que correspondiam aos seguintes recortes: História Geral do Brasil, História das Explorações Geográficas, História das Explorações Arqueológicas e Etnográficas, História Constitucional e Administrativa, História Parlamentar, História Econômica, História Militar, História Diplomática e História Literária e das Artes. ${ }^{10}$ Os especialistas que contribuíssem com artigos inéditos poderiam tratar de qualquer assunto segundo essa divisão, desde que respeitassem também as balizas temporais entre 1500 e 1871, ou seja, do descobrimento do país à promulgação da lei do Ventre Livre. Essa cronologia pontuava momentos específicos da história nacional, enfatizava a marca empreendedora do império português e certo conservadorismo da agremiação em recuperar os acordos diplomáticos sobre questões territoriais e o tráfico de africanos, a ação reformadora de protestantes holandeses em Pernambuco, o exercício do poder moderador do imperador D. Pedro II, o devassamento do território pelos jesuítas e bandeirantes paulistas, a contribuição etnográfica dos jesuítas para a narrativa de cronistas e a manifestação de sentimentos constitutivos entre o Brasil e o Reino de Portugal. Nos limites deste artigo, podemos apenas apontar que as teses demonstravam uma preocupação com o aspecto mais cívico da história brasileira, identificado à relevância e ao orgulho do seu passado para circunscrever a direção moral do seu futuro.

A partir desse momento, Ramiz adotou o patriotismo como axioma da sua concepção de história, reflexo de um fenômeno mundial que tomou conta de instituições e países em decorrência da deflagração da Primeira Guerra Mundial (GUIMARÃES 2006a). A iniciativa tomada pelo IHGB foi a de estimular novas pesquisas, materiais e métodos que tratassem do civismo a partir de tópicos e personagens esquecidos ou descartados nos primeiros anos do governo republicano e que reafirmassem o compromisso da instituição com a

\footnotetext{
${ }_{9}^{9}$ Ramiz Galvão atuou no IHGB durante muitas décadas, ocupando cargos e posições distintas, como temos destacado aqui. Ao longo do período em que pertenceu à agremiação, trabalhou diretamente com intelectuais como o Barão Homem de Melo, Joaquim Fernandes Pinheiro, Max Fleiuss, Conde Afonso Celso, Capistrano de Abreu, João Ribeiro, Basílio de Magalhães, Afrânio Peixoto, dentre muitos outros.

10 Essa divisão temática é similar à classificação adotada no Catálogo da Exposição de História e Geografia, de 1881. Para Guimarães (2006a), o Congresso de 1914 seguiu a tipologia do manual Introdução aos Estudos Históricos, de Charles-Victor Langlois e Charles Seignobos (1898). Entretanto, o IHGB priorizava nos "programas históricos" da sua revista temáticas indígenas, arqueológicas, literárias, econômicas, etc., como a própria autora analisou em sua tese de doutorado sobre a fase monárquica da agremiação (GUIMARÃES 1995).
} 
escrita de uma história brasileira intimamente ligada ao seu passado colonial e monárquico. ${ }^{11}$ Assim, ele recorreu ao passado em busca de manifestações cívicas de historiadores, nacionais ou estrangeiros, que teriam contribuído com obras meritórias, assentadas na consulta e na análise de documentos fidedignos. O sentimento patriótico relacionado ao trabalho do historiador estava associado a uma postura ética perante o arquivo, traduzida na busca incansável pela verdade dos acontecimentos. No entanto, essa não era a única tarefa do profissional e do seu campo. Havia também a necessidade de construir uma síntese histórica, baseada no controle do historiador sobre as fontes primárias e não necessariamente na formulação de um discurso totalizante, que desprezasse completamente a tradição erudita e as lições que o passado ainda poderia oferecer ao presente. ${ }^{12}$

No Segundo Congresso de História Nacional, realizado dezessete anos depois, foram mantidas as diligências em relação ao patriotismo e ao civismo; os organizadores, contudo, agora se concentraram na temática relativa à Independência, partindo do estudo da figura de D. Pedro I até o golpe da Maioridade, em 1840. Interessava aos membros do IHGB contemplar trabalhos que demarcassem a evolução da sociedade brasileira a partir de episódios decorrentes de ações individuais que não pudessem afetar a paz e a concórdia nacional.

No período compreendido entre esses eventos, a instituição promoveu outros dois projetos, o Congresso Internacional de História da América e o Dicionário Histórico, Geográfico e Etnográfico do Brasil, ambos em 1922, como parte das comemorações do centenário da Independência. Também eles contaram com a participação de Ramiz Galvão. Para o Congresso de História da América, a comissão organizadora calculou a realização de trinta sessões de trabalho, cujo objetivo era discutir o conhecimento recíproco existente em todos os países americanos, aliando questões políticas a assuntos dos diferentes campos da história. ${ }^{13}$ Ramiz Galvão atuou como presidente efetivo e como avaliador dos trabalhos científicos escritos pelos participantes. Ele seguiu o padrão adotado no congresso anterior, delimitando que os anais tivessem uma parte introdutória, dedicada ao conhecimento geral do continente, e, na seguinte, a apresentação de teses sobre os ramos do conhecimento histórico, que iam das explorações dos territórios aos avanços no campo da literatura e das artes. No total, foram publicadas noventa e nove teses, sendo um terço delas de autores estrangeiros. As bases para a elaboração da História Geral da América seguiam as prerrogativas de outros projetos comemorativos, que partiam dos descobrimentos até chegar à constituição política atual, mas havia ainda

\footnotetext{
11 É importante destacar que uma das atividades planejadas pela organização do Primeiro Congresso de História Nacional era realizar uma excursão com os congressistas à cidade de Ouro Preto, considerada já nessa época como uma das principais relíquias coloniais brasileiras. Sobre a relação entre os intelectuais do Rio de Janeiro com a cidade mineira, consultar Gomes (1993).

${ }_{12}$ Como não houve um rompimento claro com o programa oitocentista da instituição, optamos por compreender essa síntese como uma preocupação com a finalização das pesquisas e a construção de uma explicação preocupada com a objetividade da narrativa.

${ }_{13}$ Cf. Regulamento geral do Congresso Internacional de História da América (INSTITUTO 1925, v. 1). Sobre o Congresso de História da América de 1922, ver Ribeiro da Silva (2011) e Guimarães (2005).
} 
muitos pontos especiais, "bastante arrojados para a historiografia praticada no início do século XX" (GUIMARÃES 2006a, p. 202), já que as singularidades de cada cultura estavam cada vez mais inseridas nos campos do social. Se por um lado, a história adquiria estabilidade através de movimentos de repetição, onde se verificava aspectos comuns entre diversos países americanos, ela também desperdiçava algumas características locais.

Na coordenação do Dicionário Histórico, Geográfico e Etnográfico do Brasil, Ramiz Galvão, junto a uma equipe proveniente das principais instituições de saber do país, com nomes como Augusto Tavares de Lyra, Aurelino Leal, Laudelino Freire, Henrique Morize, Afrânio Peixoto, entre outros, concebeu esse material como referência para o público leigo, que ignorava o conhecimento científico produzido no país. A estrutura formal do trabalho foi elaborada a partir de questionários que atendiam às subdivisões do conhecimento histórico e das respostas recebidas pelos diversos colaboradores selecionados entre os estados brasileiros, que serviriam como instrumentos para a produção dos verbetes publicados na obra. Para evitar a dispersão e precariedade das informações, a comissão solicitou às autoridades somente "dados seguros e autênticos sobre os acidentes geográficos, etnográficos e históricos da região, que lhes eram familiares ou que superintendiam" (GALVÃO 1922, v. 1, p. VI). Contudo, mesmo com o apoio do governo republicano, a iniciativa não teve resultado satisfatório, pois os dados chegaram de forma incompleta e pouco aprofundada.

A proposta do Dicionário, mais uma vez, possui semelhanças com o projeto do Catálogo e da Exposição de História e Geografia do Brasil. Quando da organização do evento e da publicação, Ramiz e os funcionários da Biblioteca Nacional enviaram uma carta para diversas autoridades das províncias do Império, solicitando informações autênticas sobre as histórias locais que pudessem auxiliar as futuras pesquisas, servindo assim como fontes sobre o passado e elevando a instituição ao influente lugar de arquivo. O retorno das províncias fora o mesmo dos estados e dos municípios, o que obrigara os funcionários a reverem as suas estratégias e a contar diretamente com os seus pares mais próximos. ${ }^{14}$

Nessa publicação, Ramiz Galvão ficou responsável pela preparação do verbete "Biografia", que subdividiu em Chefes de estado (1815-1889), Regência provisória, Regência permanente trina, Regência una, Segundo Império e Período republicano. A elaboração desses perfis foi bastante objetiva e desrespeitou os critérios da pesquisa detalhada exigidos no questionário inicial; desse modo, a preocupação com uma narrativa biográfica que se construiu progressivamente no IHGB desde a criação do seu periódico foi suplantada, nesse verbete, pelo

\footnotetext{
${ }^{14} \mathrm{O}$ cuidado em solicitar às províncias auxílio a partir do preenchimento de questionários remonta também a um tipo de prática muito comum no interior do IHGB e que, mais tarde, teve continuidade na Academia Brasileira de Letras (Cf.: RODRIGUES 2001). Vale ressaltar que em alguns dos chamados "textos fundadores" do IHGB já estava presente a ideia de que escrever a história pátria e coligir seus documentos deveriam ser tarefas a serem desenvolvidas coletivamente. Ramiz Galvão, nesse sentido, parece herdeiro desse tipo de trabalho historiográfico e intelectual, muito embora o fato de ter se dedicado à compilação, patrimonialização e publicação de documentos tenha reservado a ele um lugar de menor prestígio do que aquele ocupado por outros intelectuais, dedicados à produção de obras de teor mais analítico ou interpretativo.
} 
modelo baseado exclusivamente na determinação dos fatos históricos. ${ }^{15}$ Os protagonistas foram identificados por suas posições políticas, sendo que a marcha coletiva do tempo, representada pelo centenário da Independência, apareceu como um elemento secundário, submetido aos desígnios políticos.

A elaboração desse verbete não foi a única experiência de Ramiz Galvão como biógrafo. Ele se tornou o orador oficial do Instituto em 1912 e tinha o dever de preparar os necrológios dos sócios recém-falecidos. O desenvolvimento desse gênero historiográfico foi repensado pelos sócios no regime republicano, assumindo uma posição diferente daquela ocupada no período monárquico. A partir dos estatutos de 1890, as biografias foram perdendo prestígio na Revista, apesar da sobrevivência da comissão encarregada de "escrever a história sucinta de todos os nacionais e estrangeiros, que se assinalaram por serviços prestados ao Brasil" (REVISTA 1890, p. 641). Os homens não precisavam mais ser comparados às figuras heróicas, que se caracterizavam pela retórica avolumada das suas ações. As exigências da escrita biográfica ficaram mais singelas, contendo indicações básicas sobre o nome, a profissão, o local e a data de nascimento e morte, além de serviços prestados e obras publicadas, "tudo isto acompanhado de conveniente juízo crítico a respeito dos seus atos" (REVISTA 1890, p. 641). A avaliação se tornou menos criteriosa no decorrer dos números do periódico, cabendo muitas vezes à lembrança dos sócios e de outros personagens históricos, às menções do orador oficial, ou ainda, ao expediente administrativo da instituição, registrado nas atas do ano corrente. Assim, as biografias deixaram de fazer parte do universo de preocupações historiográficas para servir como registro de feitos esporádicos e de contribuições pontuais desses homens na história da instituição.

Desde seus primeiros discursos sobre os sócios falecidos no século dezenove até o penúltimo ano da sua vida, Ramiz Galvão escreveu mais de setenta textos, grande parte deles preparada na década de 1930, quando sua atuação no Instituto Histórico ficou cada vez mais centrada nas suas atividades como orador. No entanto, ele não cedeu completamente às restrições dos estatutos, pois concebia a recordação dos mortos como forma de agradecimento pelos serviços prestados à Pátria. Em sua opinião, "seria um delito esquecer os bons", aqueles "que se despediram da vida depois de uma carreira laboriosa e fecunda, cheia de serviços, às vezes dos mais relevantes, às letras, às ciências e à Pátria". Rememorá-los era um dever sagrado, e seu cumprimento significava nada menos que a antecipação do "julgamento definitivo da História" (GALVÃO 1918, p. 539-40).

Pelos elogios fúnebres, Ramiz procurou estabelecer um quadro favorável da história brasileira, mesmo quando não havia protagonistas de episódicos heróicos. Aqueles homens possuíam virtudes naturais, que os acompanhavam em todas as fases das suas vidas e faziam com que eles desenvolvessem seus talentos e conquistassem seus cargos, sempre em benefício da sociedade. Os necrológicos do autor adquiriram uma significação cada vez mais conservadora

\footnotetext{
${ }^{15}$ Sobre a constituição das biografias como gênero historiográfico orientado pelo IHGB, ver Oliveira (2011).
} 
ao combinar os valores da ética e da moral cristã com os critérios da verdade cientifica. Nesse momento da sua carreira, ele já não tomava a crítica histórica como principal ferramenta metodológica; desta forma, se antes a sua trajetória foi admirada pelo seu trabalho zeloso com as fontes e pela realização de ambiciosos projetos institucionais, no final do seu percurso profissional a sua atuação como historiador se assemelhou à função de um religioso que se preocupava com qualidades espirituais.

Por fim, é preciso comentar brevemente o papel exercido por Ramiz Galvão na organização da Revista do IHGB durante o período em que foi seu diretor, de 1912 a 1933. De acordo com suas palavras, ele foi escolhido para a função porque sempre teve "por norma não desobedecer à voz do comando, quando se trata[va] de servir aos interesses da Pátria" (GALVÃo 1912, p. 5). Esse entusiasmo cívico, generalizado entre os sócios, renovou os projetos acadêmicos da instituição e, por extensão, de seu periódico, que manteve a linha editorial de publicação de fontes legítimas e de artigos baseados na investigação rigorosa dos arquivos, mas também passou a revisar algumas temáticas obscurecidas pela política monárquica, como os movimentos revolucionários contra a metrópole portuguesa ocorridos entre os séculos XVIII e XIX. Tal postura revisionista, aliás, foi adotada não só na edição da Revista do IHGB, mas também no Primeiro e no Segundo Congressos de História Nacional e no Dicionário Histórico, Geográfico e Etnográfico do Brasil, que comentamos anteriormente. Ramiz e os outros sócios não abandonaram os "processos mais apurados da crítica moderna" para as análises documentais, mas compreendiam que essa etapa deveria servir futuramente para trabalhos de síntese. Ele, em particular, entendia claramente qual era o seu desígnio como historiador do presente, apresentando-se frequentemente como organizador de um campo constituído pela verificação documental. Segundo essa perspectiva, o ofício do historiador da sua época seria superado por uma nova prática historiográfica, já que o conhecimento do passado não exigiria mais correções, ficando solidamente estabelecido como disciplina.

\section{Considerações finais}

Como forma de encerrar esse artigo, podemos retomar as perguntas seminais propostas por Michel de Certeau em seu texto "A operação historiográfica": o que "fabrica" o historiador quando faz história? Para quem trabalha? O que produz? Certamente, as respostas para essas questões não são únicas, e dependem da maneira como uma sociedade define o que é válido ou não para a historiografia.

Analisar a figura e a atuação de Ramiz Galvão a partir desse universo de questões propostas por Michel de Certeau nos pareceu profícuo por dois motivos principais, sendo que o primeiro deles guarda relação com o momento em que esse longevo letrado viveu. Ramiz iniciou sua trajetória intelectual numa conjuntura em que uma sociedade letrada determinada ocupava o lugar central na definição das regras válidas para a escrita da história; essa sociedade, o IHGB, era por sua vez profundamente marcada pelas relações que mantinha 
com o poder imperial e pela tarefa de constituição de um passado nacional. Esse espaço não era, como vimos, o único sintonizado com esse projeto historiográfico, já que, no interior da Biblioteca Nacional, Ramiz Galvão procurava remodelar essa instituição de maneira que também se tornasse um espaço de pesquisa e de produção para os historiadores. Se no início e no auge da sua trajetória ele atuou fortemente em algumas das mais importantes instituições dedicadas à tarefa de construção de uma memória nacional (empenhando-se no trabalho de coleta, crítica, constituição e divulgação de um patrimônio documental), ao final de sua vida as regras do "jogo historiográfico" pareciam ser outras. Como lembra Marieta de Moraes Ferreira, a partir dos anos 1930 o conhecimento histórico passou por um processo de profissionalização profundamente marcado pelo surgimento dos primeiros cursos universitários de história no país. Embora a importância do IHGB fosse reconhecida (e ainda se mantivesse), também despontavam críticas à historiografia produzida no interior do Instituto, entendida por alguns como excessivamente política, patriótica e consagradora das grandes figuras nacionais (FERREIRA 2013, p. 10). No caso de Ramiz, sua constante atualização em relação aos métodos e às práticas historiográficas se perdeu nos textos escritos na sua última década de vida, quando uma posição mais conservadora acabou ficando registrada como memória da sua atuação como historiador.

O segundo motivo diz respeito ao "produto" do trabalho de Ramiz Galvão, isto é, aquilo que poderíamos chamar de obra desse autor - sem desconsiderar que a noção de "obra", tal como a de "autor", devem ser analisadas criticamente, por sugerirem uma unidade de produções elaboradas de forma descontínua, conforme indicado por Michel Foucault, entre outros. Como vimos, Ramiz dedicouse a tarefas de editoração, organização de acervos e eventos, elaboração de periódicos e divulgação científica, o que fez com que se situasse num lugar a partir do qual se comunicava tanto com seus pares, quanto com um público maior e menos especializado, que era atingido principalmente pelos dicionários e exposições que viabilizava. Nesse sentido, a figura de Ramiz Galvão permite analisar como a tarefa de compor um passado para a nação brasileira envolvia múltiplas práticas, projetos, públicos e espaços.

Talvez essa seja uma pista interessante para entendermos a maneira como ele foi "lido" por seus biógrafos e por outros historiadores: como alguém um tanto "fora de lugar", um historiador na Biblioteca Nacional, um bibliotecário no IHGB, alguém cujo trabalho foi marcado, fundamentalmente, por obras de compilação, sem grande valor do ponto de vista historiográfico. Entretanto, se ao final de sua vida, já bastante idoso, Ramiz Galvão parecia antecipar demandas que eram novidades no que diz respeito ao trabalho do historiador, em um momento importante de sua trajetória, circulando pelo IHGB e pela BN, ele estava sintonizado com as regras que pela tradição definiam a produção historiográfica no seu tempo. 


\section{Referências bibliográficas}

ASSOCIAÇÃO do Quarto Centenário do Descobrimento do Brasil. Livro do Centenário (1500-1900). Rio de Janeiro: Imprensa Nacional, 19001910.

BIBLIOTECA NACIONAL. Catálogo da Exposição de História do Brasil realizada pela Biblioteca Nacional do Rio de Janeiro a 2 de dezembro de 1881. Brasília: Editora do Senado Federal, 2000. 3 v.

. Anais da Biblioteca Nacional. Rio de Janeiro: G. Leuzinger e Filhos, 1876-1882.

CALDEIRA, Ana Paula Sampaio. O bibliotecário perfeito: o historiador Ramiz Galvão na Biblioteca Nacional. Tese (Doutorado em História, Política e Bens Culturais) - Programa de Pós-Graduação em História, Política e Bens Culturais, Centro de Pesquisa e Documentação de História Contemporânea do Brasil, Fundação Getúlio Vargas, Rio de Janeiro, 2015.

. Ramiz Galvão e o projeto de uma Biblioteca Nacional. In: GOMES, Angela de Castro; HANSEN, Patrícia. Intelectuais mediadores. Práticas culturais e ação política. Rio de Janeiro: Civilização Brasileira, 2016, p. 177-215.

CERTEAU, Michel de. A escrita da história. Rio de Janeiro: Forense, 1982.

CEZAR, Temístocles. Como deveria ser escrita a história do Brasil no século XIX. Ensaio de História Intelectual. In: PESAVENTO, Sandra. História cultural: Experiências de Pesquisa. Porto Alegre: UFRGS, 2003, p. 173208.

. Lição sobre a escrita da história. Historiografia e nação no Brasil do século XIX. Diálogos, v.8, n. 1, p. 11-29, 2004.

DOSSE, François. Os três mastros entre dois recifes. A história entre vigilância e ficção. In: FERREIRA, Marieta de Moraes. Memória e identidade nacional. Rio de Janeiro: FGV, 2010, p. 15-30.

. Michel de Certeau et l'écriture de l'histoire. Vingtième Siècle - Revue d'histoire, n. 78, p. 145-156, 2/2003.

DUTRA, Eliana. A tela imortal. O Catálogo da Exposição de História do Brasil de 1881. Anais do Museu Histórico Nacional, v. XXXVII, p. 159-79, 2005.

ENDERS, Armelle. Os vultos da nação. Fábrica de heróis e formação de brasileiros. Rio de Janeiro: FGV, 2014.

FARGE, Arlette. Le goût de I'archive. Paris: Seuil, 1989.

FERREIRA, Marieta de Moraes. A história como ofício. A constituição de um campo disciplinar. Rio de Janeiro: FGV, 2013.

FOUCAULT, M. A arqueologia do saber. Rio de Janeiro: Forense Universitária, 1997. 
A ordem do discurso. São Paulo: Loyola, 2010.

GALVÃO, Ramiz. Frei Camillo de Monserrate. Estudo biográfico. In: Anais da Biblioteca Nacional. Rio de Janeiro: Tipografia Leuzinger e Filhos, 1887. . Introdução. In: IHGB. Dicionário Histórico, Geográfico e Etnográfico do Brasil. Rio de Janeiro: Imprensa Nacional, 1922. v. 1.

. Introdução. Revista do Instituto Histórico e Geográfico Brasileiro, t. 75 , v. 125 , p. 5-6, 1912.

. Discurso do orador do IHGB [Elogios fúnebres]. Revista do Instituto Histórico e Geográfico Brasileiro, t. 83, v. 137, p. 539-553, 1918.

GOMES, Angela de Castro. A República, a história e o IHGB. Belo Horizonte: Argvmentvm, 2009.

Essa gente do Rio... Os intelectuais cariocas e o modernismo. Estudos Históricos, v. 6, n. 11, p. 62-77, 1993.

GRAFTON, Anthony. As origens trágicas da erudição. Campinas: Papirus, 1998.

GUIMARÃES, Lúcia Maria Paschoal. Circulação de saberes, sociabilidades e linhagens historiográficas: dois congressos de História Nacional (1914 e 1949). In: GUIMARÃES, Manoel Luiz Salgado. Estudos sobre a escrita da história. Rio de Janeiro: 7Letras, 2006a, p. 162-181.

Da escola palatina ao Silogeu: Instituto Histórico e Geográfico Brasileiro (1889-1938). Rio de Janeiro: Museu da República, 2006b.

Debaixo da imediata proteção de Sua Majestade Imperial: a Instituto Histórico e Geográfico Brasileiro (1838-1889). Revista do Instituto Histórico e Geográfico Brasileiro, n. 388, jul.-set. 1995.

- Limites políticos de um projeto intelectual para a integração dos povos do Novo Mundo: o Primeiro Congresso Internacional de História da América (1922). Topoi, v. 6, n. 10, p. 192-212, jan./jun. 2005.

GUIMARÃES, Manoel Luiz Salgado. Nação e civilização nos trópicos. O Instituto Histórico e Geográfico Brasileiro e o projeto de uma história nacional. Estudos Históricos, n. 1, p. 5-27, 1988.

. Historiografia e nação no Brasil (1838-1857). Rio de Janeiro: EdUERJ, 2011.

HARTOG, François. A história de Homero a Santo Agostinho. Belo Horizonte: Ed. UFMG, 2001.

HRUBY, Hugo. O século XIX e a escrita da história do Brasil: diálogos na obra de Tristão de Alencar Araripe (1867-1895). Tese (Doutorado em História). Programa de Pós-Graduação em História, Pontifícia Universidade Católica do Rio Grande do Sul, Porto Alegre, 2012.

INSTITUTO HISTÓRICO E GEOGRÁFICO BRASILEIRO. Anais do Congresso Internacional de História da América. Rio de Janeiro: Imprensa 
Nacional, 1925, v. 1.

KRIEGEL, Blandine. L'histoire à I'age classique. Paris: PUF, 1988, 4 v.

MACEDO, Adriana Mattos Clen. Método e escrita da história em Benjamin

Franklin Ramiz Galvão (1846-1938). Tese (Doutorado em História) Programa de Pós-Graduação em História Social, Universidade Federal do Rio de Janeiro, Rio de Janeiro, 2013

MAIGRET, Éric. Les trois héritages de Michel de Certeau: un projet éclaté d'analyse de la modernité. Annales. Histoire, Sciences Sociales, v. 55, n. 3, p. 511-49, 2000.

MARTINS, Wilson. História da inteligência brasileira. São Paulo: Cultrix, 1950.

MOMIGLIANO, Arnaldo. As raízes clássicas da historiografia moderna. São Paulo: EDUSC, 2004. . História antiga e o antiquário. Anos 90, v. 21, n. 39, p. 19-76, 2014.

OLIVEIRA, Maria da Glória de. Escrever vidas, narrar a história: a biografia como problema historiográfico no Brasil oitocentista. Rio de Janeiro: FGV, 2011.

. Crítica, método e escrita da história em João Capistrano de Abreu. Rio de Janeiro: FGV, 2013.

58

RIHGB. Revista do Instituto Histórico e Geográfico Brasileiro, t. 53, parte 2, 1890.

RIBEIRO DA SILVA, Ana Paula Barcelos. Diálogos sobre a Escrita da História: Brasil e Argentina (1910-1940). Brasília: Fundação Alexandre de Gusmão, 2011.

RICOEUR, Paul. A história, a memória e o esquecimento. Campinas: Unicamp, 2007.

RODRIGUES, João Paulo. A dança das cadeiras. Literatura e política na Academia Brasileira de Letras (1896-1913). Campinas: Unicamp, 2001.

RODRIGUES, José Honório (Org.). Correspondência de Capistrano de Abreu. Rio de Janeiro: Instituto Nacional do Livro, 1954.

TURAZZI, Maria Inês. Imagens da nação: a Exposição de História do Brasil de 1881 e a construção do patrimônio iconográfico. STEPHAN, Beatriz Gonzales e ANDERMANN, Jens (Org.). Galerias del progreso. Museus, exposiciones y cultura visual en América Latina. Rosário: Beatriz Viterbo, 2006.

TURIN, Rodrigo. Uma nobre, difícil e útil empresa: o ethos do historiador oitocentista. História da Historiografia, n. 2, p. 12-28, 2009. 